\title{
Vascular Invasion, Satellite Nodules and Absence of Tumor Capsule Strongly Correlate with Disease-Free Survival and Long-Term Outcome in Patients Resected for Hepatocellular Carcinoma
}

\author{
Benedetta Pesi, Luca Moraldi, Daniela Zambonin, Francesco Giudici, Tiziana Cavalli, \\ Rami Addasi, Francesca Leo, Stefano Scaringi, Giacomo Batignani* \\ Gastro-Intestinal Surgery Unit, Department of Surgery and Translational Medicine, Careggi University Hospital, \\ Florence, Italy \\ Email: benedettaps@gmail.com, violamor@tiscali.it, daniela.zambonin@gmail.com, \\ francesco.giudici1@gmail.com, tiziana.cavalli@gmail.com, ramiaddasi@hotmal.com, \\ francescaleo2010@gmail.com, stefano.scaringi@aouc.unifi.it, ${ }^{*}$ g.batignani@unifi.it
}

Received 15 September 2014; revised 10 October 2014; accepted 8 November 2014

Academic Editor: Shashidhar S. Jatiani, Mt. Sinai Medical Center, USA

Copyright (C) 2014 by authors and Scientific Research Publishing Inc.

This work is licensed under the Creative Commons Attribution International License (CC BY). http://creativecommons.org/licenses/by/4.0/

(c) (i) Open Access

\section{Abstract}

Background: Hepatocellular carcinoma (HCC) is one of the most common cancer in the world. Liver resection (LR) is the most used therapy in well compensated liver cirrhosis and maybe used as a first-line treatment. Aim of the study is to evaluate survival rates in patients who underwent LR for HCC and to identify risk factors able to influence the prognosis. Material/Method: A retrospective study was carried out in 115 patients who underwent LR for HCC. We evaluated overall and disease-free survival rates at 1, 3 and 5 years $(y)$ and a series of variables included: type of resection, clamping, blood loss, transfusions, tumor size, presence of capsule, satellite nodules and vascular invasion. Results: The 1-, 3-, 5-y survival rates were $90.2 \%, 67 \%$ and $52.7 \%$, and disease-free survival rates were $75.3 \%, 44.7 \%$ and $28.4 \%$, respectively. We have found presence/ absence of capsulated tumor $(p=0.05)$, satellite nodules $(p=0.004)$ and vascular invasion $(p=$ $0.001)$ as factors able to influence the overall survival and the disease-free survival $(p=0.04$ for capsulated tumor, $p=0.01$ for satellite nodules and $p=0.006$ for vascular invasion). Conclusion: LR is the best therapeutic option for HCC when liver transplantation is contraindicated, with good survival rates. Presence of capsule, satellite nodules and vascular invasion are the most important factors able to influence the prognosis.

\footnotetext{
"Corresponding author.
}

How to cite this paper: Pesi, B., et al. (2014) Vascular Invasion, Satellite Nodules and Absence of Tumor Capsule Strongly Correlate with Disease-Free Survival and Long-Term Outcome in Patients Resected for Hepatocellular Carcinoma. Journal of Cancer Therapy, 5, 1344-1353. http://dx.doi.org/10.4236/jct.2014.514134 


\title{
Keywords
}

\author{
Liver Resection, Hepatocellular Carcinoma, Prognostic Factors, Vascular Invasion, Satellite \\ Nodules
}

\section{Introduction}

The incidence of hepatocellular carcinoma (HCC) is continuously increasing in the world and the surgical option still represents the gold standard in the treatment. Unfortunately, only $10 \%-20 \%$ of these patients are resectable because of tumour extension, location or multicentricity; an advanced stage of cirrhosis is also a contraindication to resection [1] [2]. In selected candidates, according to Milan criteria, liver transplantation still remains the treatment of choice. Liver resection on the other hand, is the most used therapy for HCC in well compensated liver cirrhosis (Child A score). Nevertleless, 5-year overall and disease-free survivals are low because of a high recurrence rate and/or the development of "de novo" HCCs.

The study of risk factors for recurrence may contribute to a better insight for the selection of candidates who may benefit from liver resection in order to improve long term survival.

The aim of this paper was to evaluate retrospectively the results of surgical treatment of patients affected by HCC and to find potential prognostic factors which well correlate with a better outcome and a lower recurrence rate.

\section{Patients and Methods}

A retrospective study was carried out on 115 patients who underwent curative liver resections for HCC at Unit of Gastro-Intestinal Surgery of the University of Florence between October 1990 and April 2013. The study period was started for each patient with the date of surgical procedure and ended in September 2013.

The preoperative diagnosis of HCC was based on the evidence of 2 radiologic imaging showing characteristic features of HCC, or one radiologic imaging showing characteristic features of HCC associated with alpha-fetoprotein (AFP) $>400 \mathrm{ng} / \mathrm{ml}$, or in a minority of cases, on cytologic/histologic evidence.

All patients underwent clinical examination and laboratory blood tests including hepatitis B surface antigen, antibodies to hepatitis C, aspartate aminotransferase (AST), alanine aminotransferase (ALT), serum albumin, total bilirubin, and prothrombin time. Furthermore serum tumor markers such as AFP, carcinoembryonic antigen (CEA) and carbohydrate antigen 19-9 (CA 19-9) were obtained.

All patients were staged as Child A according to the Child-Pugh classification.

Surgery was performed through a bilateral subcostal incision with a midline extension or J laparotomies.

After mobilization of the liver, intraoperative ultrasound was performed to assess the number, size of the lesions, the relation of the tumor with vascular structures and the spread of the tumor thrombus along the veins. Liver resections were based on Couinaud classification as either anatomical or non anatomical and either as major or minor (more than or less than 3 segments). Parenchymal transection was carried out using a Kelly crush technique. Intraoperative blood loss was classified as more or less than 500 cc and blood/fresh frozen plasma (FFP) were transfused if necessary.

The dimensions of the tumour were defined as the main diameter (expressed in centimeters), considering two categories (minor or equal to $5 \mathrm{~cm}$ and larger than $5 \mathrm{~cm}$ ). Peritumoral capsule and vascular infiltration were hystologically documented when present.

The follow-up program included liver function test, a serum AFP assay and abdominal ultrasonography every 3 months. Contrast computed tomography was performed every 6 months for surveillance of recurrence. The diagnosis of recurrence was based on the not-invasive diagnostic criteria for HCC used by the European Association for the Study of the Liver [3] or rarely on the cytologic/histologic evidences.

The hepatic recurrence was treated by re-resections, local ablative techniques, regional or systemic therapy or palliative treatment, depending on the size, location and number of recurrent tumor, on liver function status and on general conditions.

For the statistical analysis the distributions of all studied patients were reported with respect to their demographic and clinical characteristics and were summarized as frequencies and percentage. Primary outcome measures were overall survival (OS) and disease-free survival (DFS). Secondarily morbidity and in-hospital 
mortality were also evaluated. OS was defined as the time between intervention and death. DFS was defined as the time between intervention and disease recurrence or death, whichever occurred first. Observation time of patients without unfavorable events at the last follow-up visit was censored. The following demographic and clinical variables were investigated: presence of vascular invasion, capsule, satellites nodules, tumor size, type of resection (anatomical or non anatomical and major or minor resection), type of clamping, blood loss, blood and fresh frozen plasma (FFP) transfusions. All the variables were investigated for their impact on OS. The univariate survival curves were estimated using Kaplan-Meyer method and the differences in the survival rates between the groups were compared by the log-rank test. Significant difference was set at $\mathrm{p}$ value $<0.05$. All analyses were performed with the SPSS Medical Pack for Windows (version 21.0; SPSS, Chicago, IL, USA).

\section{Results}

The 115 patients ranged in age from 19 to 83 years, with a median age of 65.9 years. Of these patients 86 (74.7\%) had virus related cirrhosis (68 were positive for hepatitis C antibodies, 18 for hepatitis B virus-related antigen or antibodies), 24 (21\%) had no virus related cirrhosis, while 5 (4.3\%) showed a normal liver. Overall survival rates at 1-, 3- and 5-year were $90.2 \%, 67 \%$ and 52.7\%, respectively, and the median survival time was 72.3 months (Figure 1 ).

The disease-free survival rates at 1-, 3- and 5-year were $75.3 \%, 44.7 \%$ and $28.4 \%$, respectively, and the median disease-free survival time was 29.1 months (Figure 2).

Post-operative mortality was $4.1 \%$, however from 1996 at today it was reduced to $2.3 \%$.

Major liver resections were performed in 24 patients (20.8\%) and minor resections in 91 (79.2\%); 53 patients (46\%) had anatomical resections, while 62 (54\%) had not anatomical resections. Of these patients, 24 (20.8\%) did not have vascular occlusion, 39 (34\%) underwent a Pringle manoeuvre, 28 (24.4\%) had hemi-Pringle, 21 (18.2\%) had an inflow and outflow selective occlusion, 3 (2.6\%) had an inflow and outflow total occlusion during parenchymal transection. Blood loss more than 500 cc occurred in 20 (17.4\%) patients, 41 (35.6\%) had FFP transfusions, while 14 (12\%) had blood transfusions.

Of these patients, 80 (69.5\%) had tumor size lower than $5 \mathrm{~cm}$, while 35 (30.5\%) had tumor larger than $5 \mathrm{~cm}$.

The 1-, 3-, 5-year survival rates in patients with tumor size lower than $5 \mathrm{~cm}$ were $93 \%, 71 \%$ and $59 \%$, while in tumor larger than $5 \mathrm{~cm}$ were $83 \%, 56 \%$ and $40 \%(\mathrm{p}=0.22)$. The disease-free survival at 1,3 and 5 years were $92 \%, 59 \%$ and $43 \%$ vs. $78 \%, 39 \%$ and $28 \%$, in tumor lower and larger than $5 \mathrm{~cm}$ respectively $(\mathrm{p}=0.09)$.

Capsulated tumors were found in 20 patients (17.4\%) and satellites nodules in 32 (27.8\%).

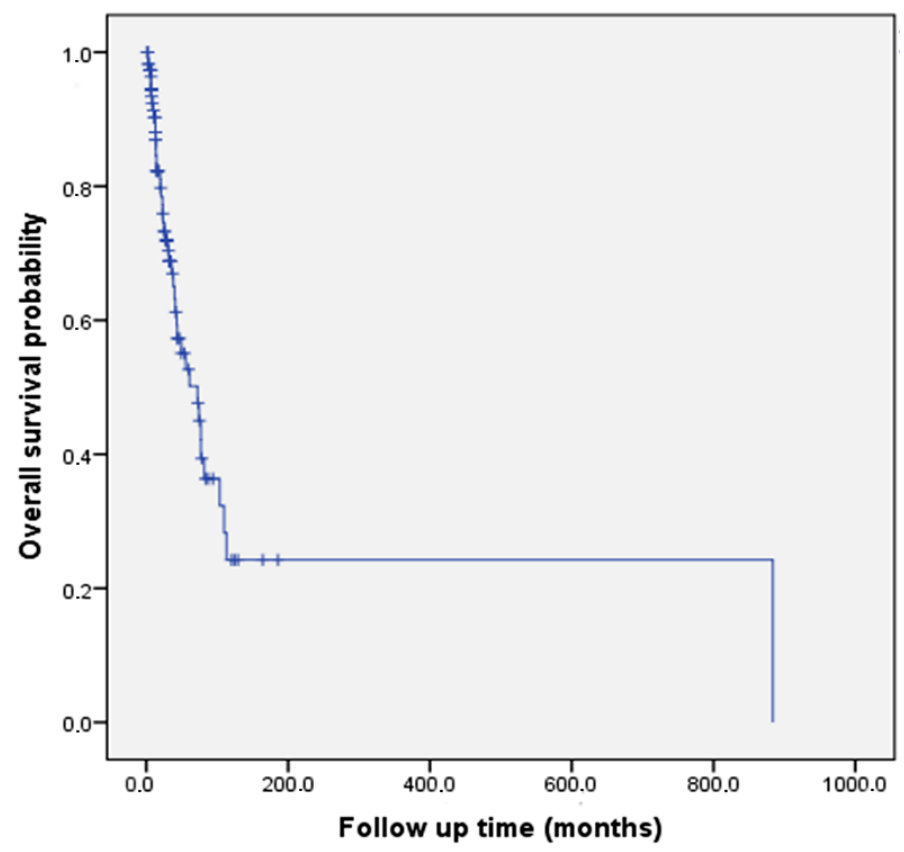

Figure 1. Overall survival rates in patients who underwent liver resection with curative intent for hepatocellular carcinoma. 
In capsulated tumor the 1-, 3-, 5-year survival rates were $95 \%, 75 \%$ and $67 \%$, while were $89 \%, 64 \%$ and $48 \%$ in not-capsulated $(\mathrm{p}=0.05)$. Disease-free survival at 1,3 and 5 years in patients with capsulated tumor were $95 \%, 68 \%$ and $53 \%$, while were $86 \%, 49 \%$ and $35 \%$ in the other patients $(\mathrm{p}=0.04)$.

Vascular infiltration was present in $32(27.8 \%)$ patients. The 1-, 3-, 5-year survival in patients with vascular invasion were $74 \%$, 38\%, 28\%, with a median survival of 25.3 months, while in the others patients were $95 \%$, $78 \%, 69 \%$, with a median survival of 81.6 months $(\mathrm{p}=0.001)$ (Figure 3$)$. Differences in disease-free survival at 1,3 and 5 years in patients with and without vascular invasion were $71 \%, 34 \%$ and $25 \%$ vs. $94 \%, 61 \%$ and $44 \%$, respectively $(\mathrm{p}=0.006)$ (Figure 4$)$.

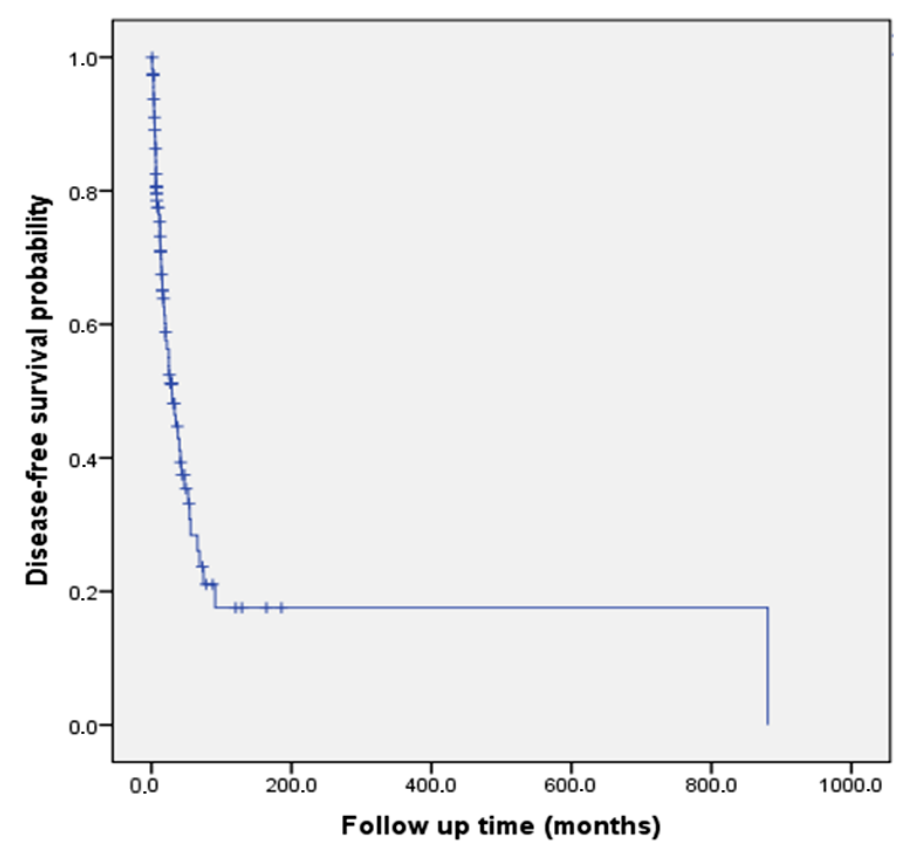

Figure 2. Disease-free survival rates in patients who underwent liver resection with curative intent for hepatocellular carcinoma.

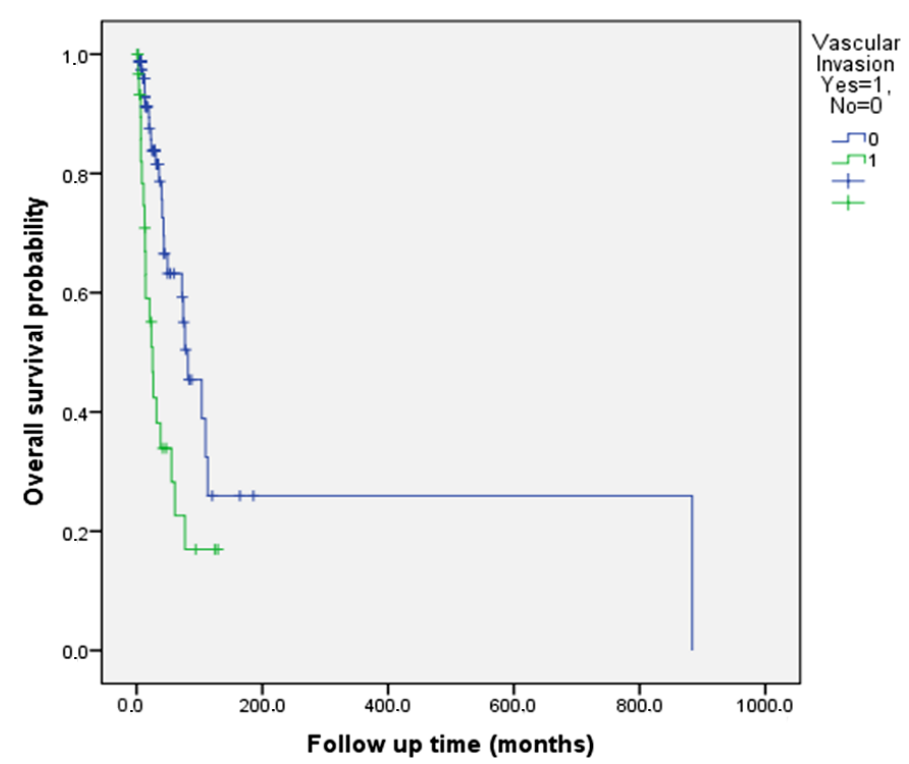

Figure 3. Survival rates in patients who underwent liver resection for hepatocellular carcinoma with or without vascular invasion. Statistical differences were present among the 2 groups $(\mathrm{p}=0.001)$. 
The 1-, 3-, 5-year survival rates in presence of satellite nodules were $90 \%, 42 \%$ and $32 \%$, with a median survival of 30.6 months, while in absence were $90 \%, 80 \%$ and $64 \%$, with a median survival of 103 months (p = 0.004) (Figure 5). Disease-free survival at 1,3 and 5 years in patients with and without satellite nodules were $84 \%$, $34 \%$ and $25 \%$ vs. $90 \%, 64 \%$ and $46 \%$, respectively ( $\mathrm{p}=0.01$ ) (Figure 6).

The characteristics of patients related to overall survival and disease-free survival with univariate analysis are shown in Table 1 and Table 2.

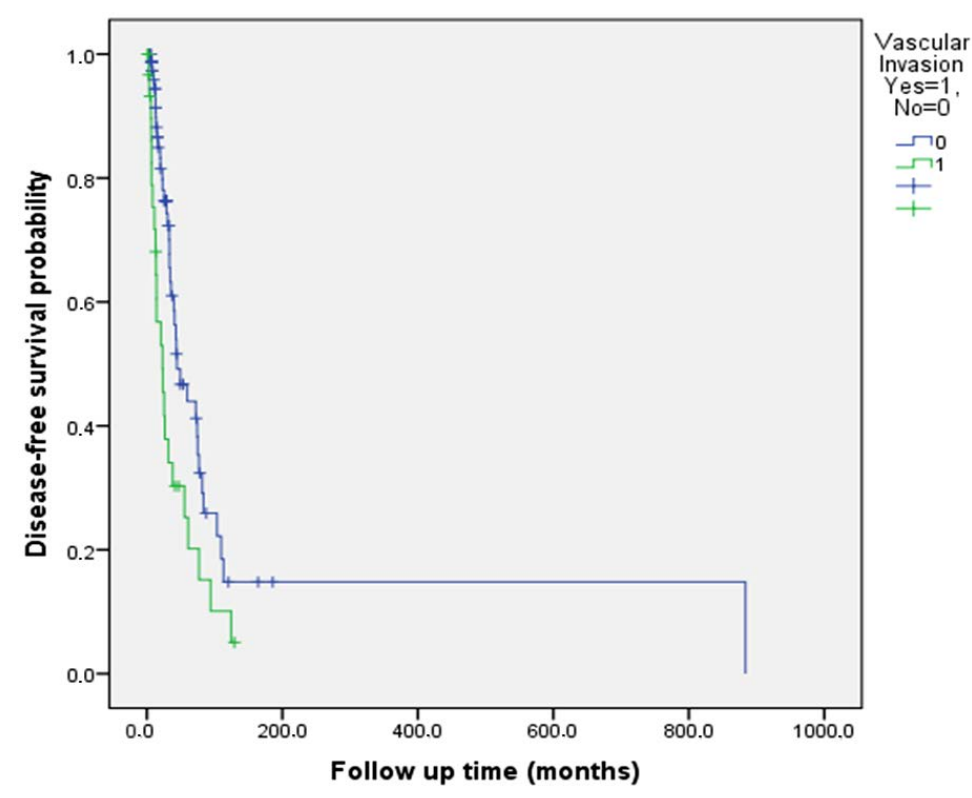

Figure 4. Disease-free survival rates in patients who underwent liver resection for hepatocellular carcinoma with or without vascular invasion. Statistical differences were present among the 2 groups $(p=0.006)$.

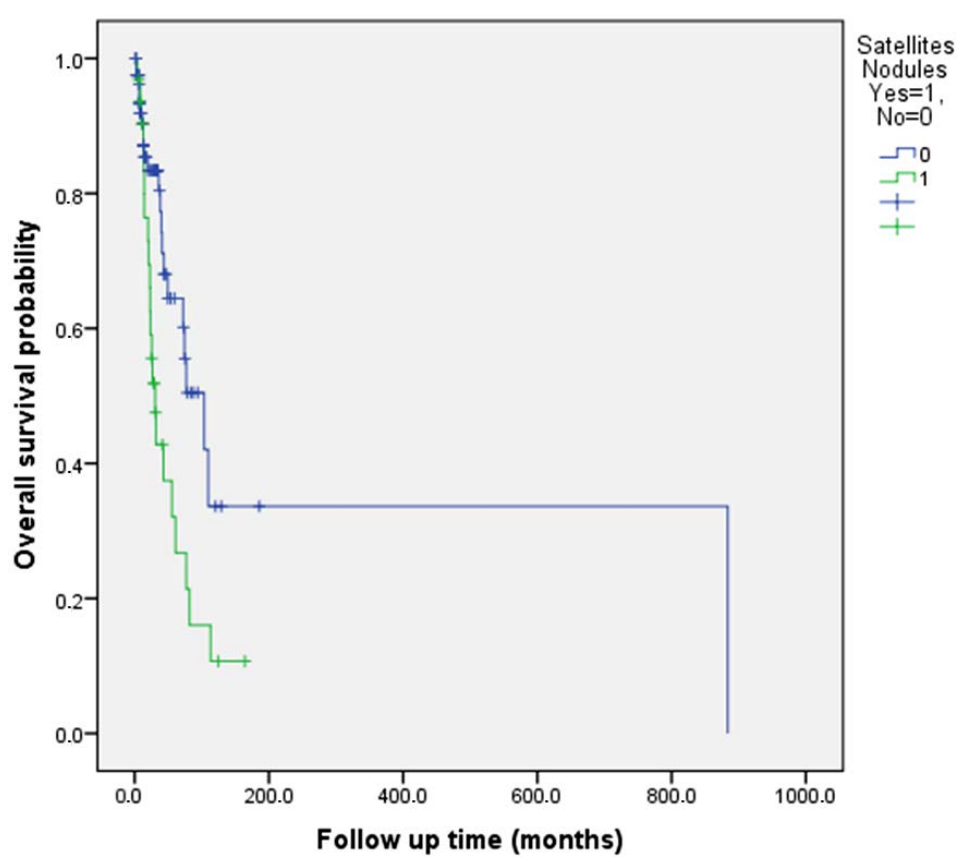

Figure 5. Survival rates in patients who underwent liver resection for hepatocellular carcinoma with or without satellites nodules. Statistical differences were present among the 2 groups $(p=0.004)$. 


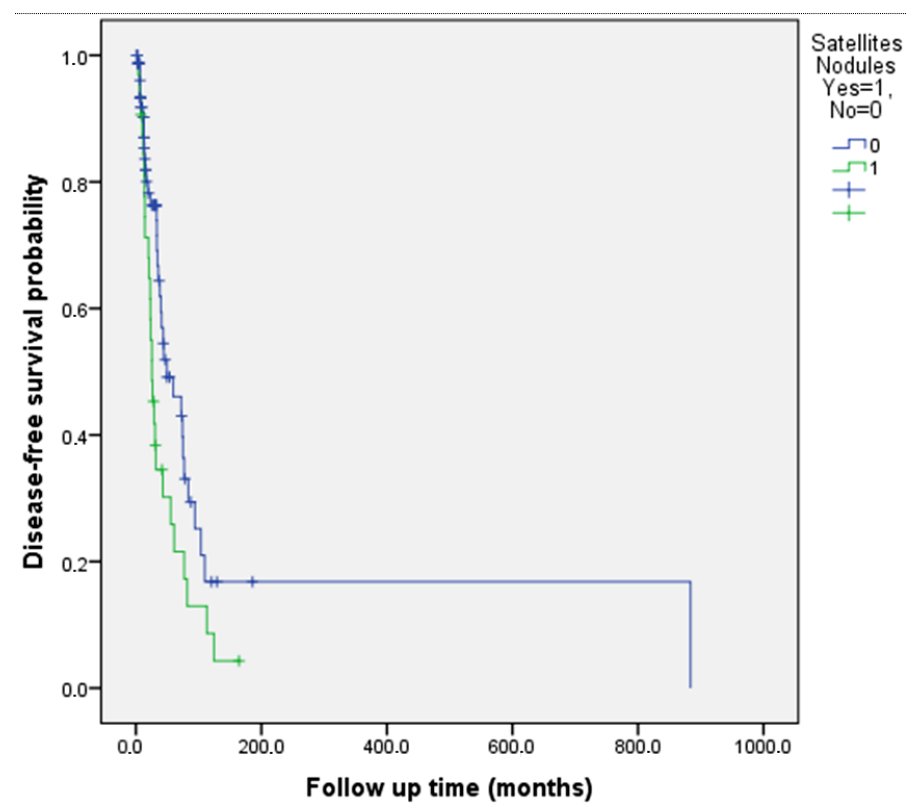

Figure 6. Disease-free survival rates in patients who underwent liver resection for hepatocellular carcinoma with or without satellites nodules. Statistical differences were present among the 2 groups $(\mathrm{p}=$ 0.001).

\section{Discussion}

The surgical resection is the gold standard treatment of hepatocellular carcinoma, in patients with transplant controindications. Patients are selected based on the hepatic functional reserve and to the state of the tumor.

Cha et al. in their study documenting an overall survival of $79 \%, 51 \%$ and $40 \%$ respectively at 1,3 and 5 years after hepatic resection, with a median survival time of 36 months [4]. Belghiti et al. [5] reported a cumulative survival of $35 \%$ and $17 \%$ at 3 and 5 years respectively in a cirrhotic population. Kanematsu et al. document an overall survival rate of $84 \%, 67 \%, 51 \%$ and $20 \%$ respectively at $1,3,5$ and 10 years, in a population of patients with cirrhosis. Vauthney et al. [6] also reported a 5 and 10 year survival of $41 \%$ and $32 \%$ respectively with a mean survival time of 26 months. The results of the Liver Cancer Study Group of Japan show a survival at $1,3,5,10$ years old, respectively, $85 \%, 64 \%, 45 \%$ and $21 \%$ [7].

In our study the overall survival rates at 1-, 3- and 5-year were $90.2 \%, 67 \%$ and $52.7 \%$, with a median survival time was 72.3 months, while the disease-free survival rates were $75.3 \%, 44.7 \%$ and $28.4 \%$, respectively, with a median disease-free survival time was 29.1 months.

Intrahospital mortality rate after sugical resection for HCC may considerably vary mainly depending on the Child-Pugh status but also on the tumor stage. Overall perioperative mortality rates reported in the literature ranges from $0.9 \%$ to $50 \%$ [4] [8]-[10]. Such a large range of variation could be interpreted as the expression of different selection criteria. The selection of potential candidates to surgical treatment represents, in our opinion, a crucial point in order to obtain low mortality rates. Besides perioperative mortality rate also depends on the improvement of surgical techniques and on the skillness of the surgical team in the treatment of cirrhotic patients in the postoperative period. The higher mortality rates in the 80 and 90 years if compared with the more recent, clearly show the improved skillness in the postoperative treatment of these patients [11]. In our analysis the post-operative mortality rate was $4.1 \%$, but it was reduced to $2.3 \%$ from 1996 at today.

HCC usually recurs in the liver itself, with a literature recurrence rates ranges from $40 \%$ to $100 \%$ [5] [12]. Recurrence may develop either from a microscopic residual disease (R1 resection) or from a "de novo" HCC which arises in a cirrhotic liver.

Torzilli et al. [13] identified bilirubin, cirrhosis, esophageal varices, tumor size, and macrovascular invasion to be statistical and independent prognostic factors for overall survival in HCC underwent liver resection.

Ko et al. [14] reported the execution of a major hepatectomy as a risk factor for intrahepatic recurrence, sup- 
Table 1. Univariate analysis of prognostic factors related to overall survival.

\begin{tabular}{|c|c|c|c|c|}
\hline Variables & $\begin{array}{l}\text { 1-Year Overall } \\
\text { Survival (\%) }\end{array}$ & $\begin{array}{l}\text { 3-Year Overall } \\
\text { Survival (\%) }\end{array}$ & $\begin{array}{l}\text { 5-Year Overall } \\
\text { Survival (\%) }\end{array}$ & P Value \\
\hline \multicolumn{5}{|l|}{ Type of resection } \\
\hline Major & 80 & 43 & 31 & \\
\hline Minor & 92 & 73 & 59 & 0.10 \\
\hline \multicolumn{5}{|l|}{ Type of resection } \\
\hline Anatomical & 91 & 67 & 53 & \\
\hline Non anatomical & 88 & 67 & 51 & 0.62 \\
\hline \multicolumn{5}{|l|}{ Type of portal clamping } \\
\hline None & 95 & 71 & 38 & \\
\hline Pringle & 93 & 54 & 54 & \\
\hline Hemipringle & 80 & 71 & 59 & \\
\hline Inflow and outflow selective occlusion & 94 & 82 & 60 & \\
\hline Inflow and outflow total occlusion & 66 & / & / & 0.23 \\
\hline \multicolumn{5}{|l|}{ Blood loss } \\
\hline$<500$ & 89 & 68 & 54 & \\
\hline$>500$ & 95 & 62 & 44 & 0.76 \\
\hline \multicolumn{5}{|l|}{ FFP transfusions } \\
\hline Yes & 90 & 67 & 47 & \\
\hline No & 90 & 66 & 60 & 0.55 \\
\hline \multicolumn{5}{|l|}{ Blood transfusions } \\
\hline Yes & 92 & 52 & 41 & \\
\hline No & 89 & 69 & 54 & 0.42 \\
\hline \multicolumn{5}{|l|}{ Capsule } \\
\hline Present & 95 & 75 & 67 & \\
\hline Absent & 89 & 64 & 48 & 0.05 \\
\hline \multicolumn{5}{|l|}{ Satellites nodules } \\
\hline Present & 90 & 42 & 32 & \\
\hline Absent & 90 & 80 & 64 & 0.004 \\
\hline \multicolumn{5}{|l|}{ Vascular Invasion } \\
\hline Present & 74 & 38 & 28 & \\
\hline Absent & 95 & 78 & 63 & 0.001 \\
\hline \multicolumn{5}{|l|}{ Tumor dimensions } \\
\hline$<5 \mathrm{~cm}$ & 93 & 71 & 59 & \\
\hline$>5 \mathrm{~cm}$ & 83 & 56 & 40 & 0.22 \\
\hline
\end{tabular}

posed that a greater extent of hepatectomy involves a greater regenerative growth that can facilitate the process of carcinogenesis in the remnant liver. Imamura et al. [15] reported a decrease in the rate of recurrence in patients underwent typical resection rather than atypical. Yamazaki et al. show a 5-year survival of 35\% versus $66 \%$, respectively, in patients underwent enucleation than segmentectomy, proposing typical resection as the best option [16]. We have not found a statistical difference about type of resection, vascular occlusion, blood loss and blood/FFP transfusions.

Cha et al. [4] document the presence of vascular invasion in $45 \%$ of cases out of 164 pts. and report that this factor is an important one to predict recurrence, together with tumor dimensions larger than $5 \mathrm{~cm}$, at a univariate analysis. Lee et al. show a 10-year survival of 31\% in patients with tumors smaller than $3 \mathrm{~cm}$ [17].

Lai et al. [18] reported a recurrence rate of $63 \%$ at 14 months after surgery and a 5-year survival of $12 \%$ in 
Table 2. Univariate analysis of prognostic factors related to disease-free survival.

\begin{tabular}{|c|c|c|c|c|}
\hline Variables & $\begin{array}{l}\text { 1-Year Disease-Free } \\
\text { Survival (\%) }\end{array}$ & $\begin{array}{l}\text { 3-Year Disease-Free } \\
\text { Survival (\%) }\end{array}$ & $\begin{array}{l}\text { 5-Year Disease-Free } \\
\text { Survival (\%) }\end{array}$ & P Value \\
\hline \multicolumn{5}{|l|}{ Type of resection } \\
\hline Major & 76 & 36 & 25 & \\
\hline Minor & 91 & 58 & 42 & 0.14 \\
\hline \multicolumn{5}{|l|}{ Type of resection } \\
\hline Anatomical & 88 & 56 & 43 & \\
\hline Non anatomical & 87 & 49 & 33 & 0.29 \\
\hline \multicolumn{5}{|l|}{ Type of portal clamping } \\
\hline None & 91 & 49 & 26 & \\
\hline Pringle & 89 & 42 & 36 & \\
\hline Hemipringle & 83 & 65 & 47 & \\
\hline Inflow and outflow selective occlusion & 90 & 66 & 48 & \\
\hline Inflow and outflow total occlusion & 66 & 1 & 1 & 0.11 \\
\hline \multicolumn{5}{|l|}{ Blood loss } \\
\hline$<500$ & 89 & 55 & 42 & \\
\hline$>500$ & 84 & 45 & 26 & 0.29 \\
\hline \multicolumn{5}{|l|}{ FFP transfusions } \\
\hline Yes & 87 & 58 & 35 & \\
\hline No & 88 & 47 & 43 & 0.64 \\
\hline \multicolumn{5}{|l|}{ Blood transfusions } \\
\hline Yes & 85 & 40 & 24 & \\
\hline No & 88 & 56 & 42 & 0.22 \\
\hline \multicolumn{5}{|l|}{ Capsule } \\
\hline Present & 95 & 68 & 53 & \\
\hline Absent & 86 & 49 & 35 & 0.04 \\
\hline \multicolumn{5}{|l|}{ Satellites nodules } \\
\hline Present & 84 & 34 & 25 & \\
\hline Absent & 90 & 64 & 46 & 0.01 \\
\hline \multicolumn{5}{|l|}{ Vascular Invasion } \\
\hline Present & 71 & 34 & 25 & \\
\hline Absent & 94 & 61 & 44 & 0.006 \\
\hline \multicolumn{5}{|l|}{ Tumor dimensions } \\
\hline$<5 \mathrm{~cm}$ & 92 & 59 & 43 & \\
\hline$>5 \mathrm{~cm}$ & 78 & 39 & 28 & 0.09 \\
\hline
\end{tabular}

117 patients with a tumor larger than $5 \mathrm{~cm}$. Ohkubo et al. [19] show that the size of the tumor influence the prognosis in patients with hepatocellular carcinoma, but emphasize that this parameter becomes statistically significant only for lesions with a diameter greater than $10 \mathrm{~cm}$. Recurrence seems also correlate with peritumoral capsule [18] [20].

In our study the tumor dimensions seems to be correlated with the recurrence, with a better disease-free survival rates in patients with tumor smaller than $5 \mathrm{~cm}(\mathrm{p}=0.09)$. The presence of peritumoral capsule shows a statistical difference on overall and disease-free survival rates, with a better survival in patients with capsulated tumor.

Kawasaki et al. [9] report a significant correlation between the absence of vascular invasion and intrahepatic 
metastasis and the disease-free survival. Hanazaki et al. [21] also observe that cirrhosis and vascular invasion predict long term survival in patients older than 70 years. Vauthey et al. [6] also confirm vascular invasion as a predictive factor for long term outcome but do not observe any significant correlation among survival and the presence of cirrhosis, grading, tumor dimension larger than $5 \mathrm{~cm}$ and free margins.

In this study the overall survival rates at 1-, 3-, 5-year survival rates were $90 \%, 42 \%$ and $32 \%$ in presence of satellite nodules versus $90 \%, 80 \%$ and $64 \%$ in absence $(\mathrm{p}=0.004)$; and $74 \%, 38 \%, 28 \%$ versus $95 \%, 78 \%, 69 \%$ in patients with and without vascular invasion $(\mathrm{p}=0.001)$. Furthermore a statistical difference were found on disease-free survival rates about presence of satellite nodules $(\mathrm{p}=0.01)$ and vascular invasion $(\mathrm{p}=0.006)$. So our study clearly shows by the means of a univariate statistical analysis that the presence of satellite nodules, vascular invasion and not-capsulated tumor are important factors correlated with overall and disease-free survival rates.

\section{Conclusion}

Liver resection is the best therapeutic option for HCC if liver transplantation is not ready available or contraindicated, with good survival rates. Dimensions of tumor have a statistical "trend" on the disease-free survival rates, with a better survival in pts with lesions $<5 \mathrm{~cm}$. Absence of capsule, presence of satellite nodules and vascular invasion are very important factors able to influence the prognosis of resectable HCC patients based on our findings.

\section{Conflict of Interests}

Authors certify that there is no actual or potential conflict of interest in relation to this article.

\section{References}

[1] Lau, W.Y. (2000) Primary Hepatocellular Carcinoma. In: Blumgart, L.H. and Fong, Y., Eds., Surgery of the Liver and Biliary Tract. W.B. Saunders, England, 1423-1450.

[2] Belghiti, J. (2008) Surgical Treatment. In: Lau, W.Y., Ed., Hepatocellular Carcinoma. World Scientific Publishing Co. Pte. Ltd., Singapore, 387-408.

[3] European Association for the Study of the Liver and European Organisation for Research and Treatment of Cancer. (2012) EASL-EORTC Clinical Practice Guidelines: Management of Hepatocellular Carcinoma. Journal of Hepatology, 56, 908-943.

[4] Cha, C., Fong, Y., Jarnagin, W.R., Blumgart, L.H. and De Matteo, R.P. (2003) Predictors and Patterns of Recurrence after Resection of Hepatocellular Carcinoma. Journal of the American College of Surgeons, 197, 753-758. http://dx.doi.org/10.1016/j.jamcollsurg.2003.07.003

[5] Belghiti, J., Panis, Y., Farges, O., Benhamou, J.P. and Fekete, F. (1990) Intrahepatic Recurrence after Resection of Hepatocellular Carcinoma Complicating Cirrhosis. Surgery, 214, 114-117.

[6] Vauthey, J.N., Klimstra, D., Franceschi, D., Tao, Y., Fortner, J., Blumgart, L. and Brennan, M. (1995) Factors Affecting Long-Term Outcome after Hepatic Resection for Hepatocellular Carcinoma. The American Journal of Surgery, 169, 28-35. http://dx.doi.org/10.1016/S0002-9610(99)80106-8

[7] Ikai, I., Itai, Y., Okita, K., et al. (2004) Report of the 15th Follow-Up Survey of Primary Liver Cancer. Hepatology Research, 28, 21-29. http://dx.doi.org/10.1016/j.hepres.2003.08.002

[8] Dalla Valle, R., Borie D., Hannoun L. and Botta G.C. (2000) Surgical Treatment of Hepatocellular Carcinoma in Cirrhosis. Digest Liver, 32, 346-352.

[9] Kawasaki, S., Makuuchi, M., Miyagawa, S., Kakazu, T., Hayashi, K., Kasai, H., Miwa, S., Hui, A.-M. and Nishimaki, K. (1995) Results of Hepatic Resection for Hepatocellular Carcinoma. World Journal of Surgery, 19, 31-34. http://dx.doi.org/10.1007/BF00316976

[10] Kanematsu, T., Furui, J., Yanaga, K., Okudaira, S., Shimada, M. and Shirabe, K. (2002) A 16 Years Experience in Performing Hepatic Resection in 303 Patients with Hepatocellular Carcinoma: 1985-2000. Surgery, 131, S153-S158. http://dx.doi.org/10.1067/msy.2002.119497

[11] Grazi, G., Ercolani, G., Pierangeli, F., Del Gaudio, M., Cescon, M., Cavallari, A. and Mazziotti, A. (2001) Improved Results of Liver Resection for Hepatocellular Carcinoma on Cirrhosis Give the Procedure Added Value. Annals of Surgery, 234, 71-78. http://dx.doi.org/10.1097/00000658-200107000-00011

[12] Matsuda, Y., Ito, T., Oguchi, Y., Nakajima, K. and Izuruka, T. (1992) Rationale of Surgical Management Recurrent 
Hepatocellular Carcinoma. Surgery, 204, 28-34.

[13] Torzilli, G., Belghiti, J., Kokudo, N., Takayama, T., Capussotti, L., Nuzzo, G., Vauthey, J.-N., Choti, M.A., De Santibanes, E., Donadon, M., Morenghi, E. and Makuuchi, M. (2013) A Snapshot of the Effective Indications and Results of Surgery for Hepatocellular Carcinoma in Tertiary Referral Centers: Is It Adherent to the EASL/AASLD Recommendations? An Observational Study of the HCC East-West Study Group. Annals of Surgery, 257, 929-937. http://dx.doi.org/10.1097/SLA.0b013e31828329b8

[14] Ko, S., Nakajima, Y., Kanehiro, H., Kin, T., Aomatsu, Y., Yoshimura, A., Taki, J., Yagura, K., Oashi, K. and Nakano, H. (1996) Influence of Associated Viral Heopatitis Status on Recurrence of Hepatocellular Carcinoma after Hepatectomy. World Journal of Surgery, 20, 1082-1086. http://dx.doi.org/10.1007/s002689900164

[15] Imamura, H., Matsuyama, Y., Tanaka, E., Okhubo, T., Hasegawa, K., Miyagawa, S., Sugawara, Y., Minagaea, M., Takayama, T., Kawasaki, S. and Makuuchi, M. (2003) Risk Factor Contributing to Early and Late Phase Intrahepatic Recurrence of Hepatocellular Carcinoma after Hepatectomy. Journal of Hepatology, 38, 200-207. http://dx.doi.org/10.1016/S0168-8278(02)00360-4

[16] Yamazaki, S. and Takayamam, T. (2008) Surgical Treatment of Hepatocellular Carcinoma: Evidence-Based Outcomes. World Journal of Gastroenterology, 14, 685-692. http://dx.doi.org/10.3748/wjg.14.685

[17] Lee, C.S., Sheu, J.C., Wang, M., et al. (1996) Long-Term Outcome after Surgery for Asymptomatic Small Hepatocellular Carcinoma. British Journal of Surgery, 83, 330-333. http://dx.doi.org/10.1002/bjs.1800830310

[18] Lai, E.C., Ng, I.O., Ng, M.M., et al. (1990) Long-Term Results of Resection for Large Hepatocellular Carcinoma: A Multivariate Analysis of Clinicopathologic Features. Hepatology, 11, 815-818. http://dx.doi.org/10.1002/hep.1840110516

[19] Ohkubo, T., Yamamoto, J., Sugawara, Y., Shimada, K., Yamasaki, S., Makuuchi, M. and Kosuge, T. (2000) Surgical Results for Hepatocellular Carcinoma with Macroscopic Portal Vein Tumor Thrombosis. Journal of the American College of Surgeons, 191, 657-660. http://dx.doi.org/10.1016/S1072-7515(00)00740-7

[20] Kemeny, F., Vadrot, J., Wu, A., et al. (1989) Morphological and Biological Features of Resected Hepatocellular Carcinoma in Cirrhotic Patients in the West. Hepatology, 9, 253-257. http://dx.doi.org/10.1002/hep.1840090215

[21] Hanazaki, K., Kajikawa, S., Shimozawa, N., Shimada, K., Hiraguri, M., Koide, N., Adaki, W. and Amano, J. (2001) Hepatic Resection for Hepatocellular Carcinoma in the Elderly. Journal of the American College of Surgeons, 192, 138-146. 
Scientific Research Publishing (SCIRP) is one of the largest Open Access journal publishers. It is currently publishing more than 200 open access, online, peer-reviewed journals covering a wide range of academic disciplines. SCIRP serves the worldwide academic communities and contributes to the progress and application of science with its publication.

Other selected journals from SCIRP are listed as below. Submit your manuscript to us via either submit@scirp.org or Online Submission Portal.
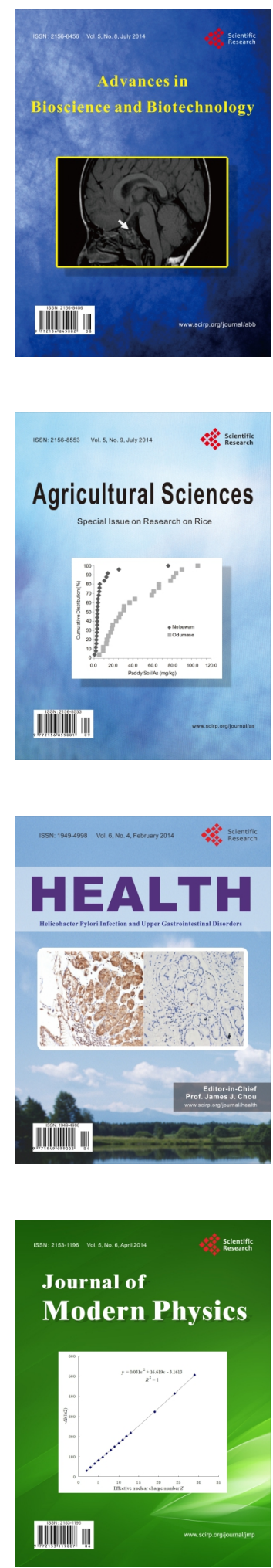
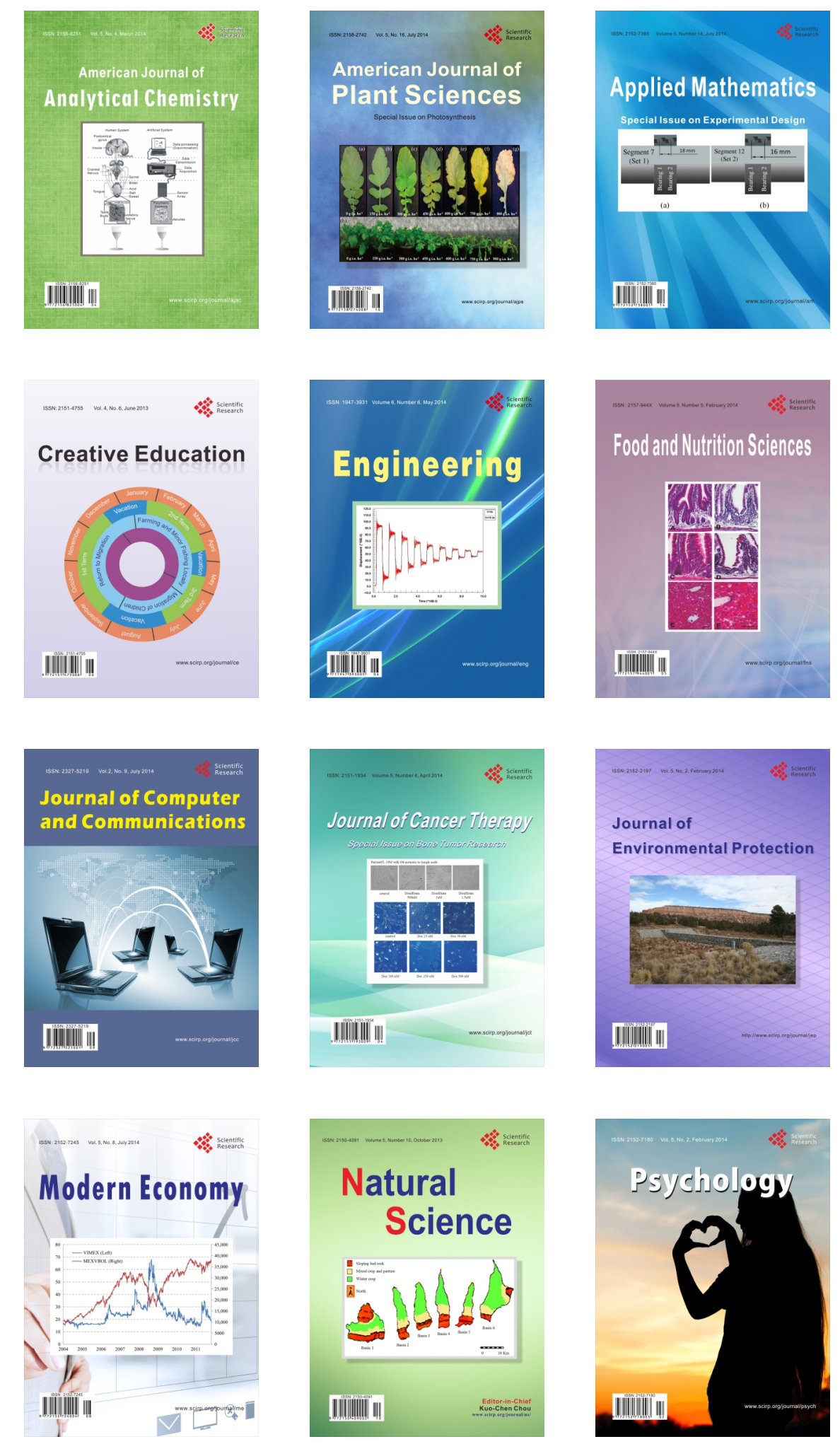